\title{
Application of Leadership Strategies Secondary to a Book Review
}

\author{
Nancy C. Brahm ${ }^{1,}$, Julie C. Kissack ${ }^{1}$, Susan M. Grace ${ }^{2} \&$ Lisa M. Lundquist ${ }^{3}$ \\ ${ }^{1}$ University of Oklahoma College of Pharmacy, Tulsa, OK 74135-2512, USA \\ ${ }^{2}$ Harding University College of Pharmacy, Searcy, AR 72149, USA \\ ${ }^{3}$ Mercer University College of Pharmacy and Health Sciences, Atlanta, GA 30341-4155, USA \\ *Corresponding author: University of Oklahoma College of Pharmacy, 4502 E. $41^{\text {st }}$ Street, 2H17, Tulsa, OK \\ 74135-2512, USA Tel: 1-918-660-3579 E-mail: nancy-brahm@ouhsc.edu
}

\author{
Received: November 19, 2012 \\ Accepted: December 11, 2012 \\ Online Published: January 5, 2013 \\ doi:10.5430/jct.v2n1p27 \\ URL: http://dx.doi.org/10.5430/jct.v2n1p27
}

\begin{abstract}
Purpose: Two-fold: [1] To evaluate available literature describing leadership management techniques and how these techniques can be used for pharmacy faculty transitioning into new academic roles and [2] To evaluate a leadership program and how it can be applied to the individual to enhance leadership skills. Methods: Literature related to pharmacist development was evaluated and a book review with a corresponding workbook was completed. Faculty members from three colleges of pharmacy participated in a focus group session. Response confidentially was maintained. This project was approved by a university institutional review board. Results: All study group members (4) participated in the focus group. Two overarching themes were unanimously identified regarding implementation of this process. The first theme was time commitment. The second was trust. These were considered essential to the team-building process. As a secondary outcome, the dynamic process of team building was acknowledged. All focus group members were pleased with the use of the book and workbook as learning tools. Conclusions: Participants expressed satisfaction with the materials used, information covered, and learning experience. They suggested additional strategies for implementation into a variety of settings, offered suggestions for future studies, and requested additional collaboration in this area.
\end{abstract}

Keywords: academia; faculty; leadership; team building

\section{Introduction}

Academic responsibilities focus on delivery of educational programs, establishing clinical practices or other service activities and scholarly activities/research projects. Successful management of these three areas requires leadership abilities. While the American Association of Colleges of Pharmacy (AACP) recognizes the need for leadership development support in graduate and postgraduate professional education (AACP, 2008; Gaither et al., 2009), roadmaps to guide development of academicians are scarce in the pharmacy literature. Mentorship programs as a strategy for junior pharmacy faculty (e.g. instructors, assistant professors) retention have been described in the literature, and were found to be effective tools, but in general have not produced outcomes that are clearly measurable (Guglielmo et al., 2011). Limiting factors for traditional mentor/mentee programs include low numbers of senior faculty $(53 \%)$ (AACP, 2008) to serve as mentors and the numerous demands already placed on the time of senior faculty at many institutions. Of the pharmacy faculty nationwide, within junior faculty $29 \%$ are female and $19 \%$ are male, whereas within senior faculty $19 \%$ are female while $33 \%$ are male. Additionally, organizational features unique to each institution, such as location at a satellite campus, scholarship requirements for promotion, responsibilities secondary to the number of open faculty positions, increased teaching load or clinical responsibilities might contribute to the faculty member's decision to serve as a mentor (Conklin \& Desselle, 2007). Fundamental leadership skills are essential to enable faculty to develop new practice sites, while working with an interprofessional team. All pharmacy programs should offer opportunities to develop leadership abilities in their faculty.

The purpose of this project was two-fold and focused on strategies or resources most applicable to facilitate leadership development for junior faculty transitioning into either academic or clinical settings. The first goal was evaluation of the literature related to pharmacy faculty leadership development programs or models. The second goal 
was evaluation of participants' perception of the use of a leadership book and accompanying workbook as a resource for developing leadership skills. This relatively inexpensive resource and process could be useful in a leadership development program for faculty at any level of academic appointment but may be most useful for junior faculty transitioning from postgraduate training into an academic or clinical position.

\section{Search methodology}

A literature review was conducted for peer-reviewed information on faculty leadership development. Databases searched included Ovid, Google Scholar, MEDLINE®, PubMed, EMBASE, and ACP Journal Club, Search Strategy from 1964 to July 2012. Search terms were self-study, college and/or school of pharmacy, faculty development, team approach, leadership, mentor, and learners. For each article found, the authors reviewed the references to identify additional relevant articles.

\section{Design}

A focus group research methodology was a priori selected to determine the participants" perceptions of the leadership skills needed to successfully transition into an academic setting. Consistent with University policies and procedures, Institutional Review Board (IRB) approval was requested and received for the study. The focus group participants, all of which self-selected to participate, consisted of an interprofessional group of college or school of pharmacy faculty from three universities. They reviewed a leadership book, The Five Dysfunctions of a Team (Lencioni, 2002) and completed an accompanying workbook (Lencioni, 2007) to develop leadership strategies in three areas: (1) the team building process, (2) concept application, and (3) functional team development.

The Five Dysfunctions of a Team (Lencioni, 2002) identifies five specific elements that are essential for effective teamwork: building trust, mastering conflict, achieving commitment, embracing accountability, and focusing on results. Each member of the group read the book, systematically completed the workbook activities and met through teleconference for one hour on six separate occasions to review the five elements and team growth. During the first teleconference, the team leader shared a number of desired objectives. Team members agreed upon outcome measures that would indicate success in achieving the identified objectives.

The focus group discussion sessions occurred after the completion of the book review and workbook activities, and were not recorded electronically. Written notes were taken by the principle investigator. All comments remained anonymous. The discussion lasted approximately 60 minutes. Participation was voluntary and participants were allowed to discontinue the teleconference at any time. The focus group questions included:

What are some of your thoughts about the skills and knowledge needed for faculty members to apply this methodology?

Would you say that you are satisfied with the level of knowledge/skill provided by the author in this area?

Why or Why Not?

What would you like to see changed about the faculty development programs in your own institution to incorporate this information?

Why?

\section{Evaluation and assessment}

Three overarching themes were identified through this focus group discussion. The first was time management: the need to schedule time for personal development and group interactions. Taking the time to get to know other faculty members on a personal level and the commitment to the process of team building were specifically highlighted. The second was trust. The group acknowledged the importance of the dynamic process of team building, which involves trust in the individual members and the process. In response to the first question regarding the skills and knowledge needed to apply this methodology, the group identified the need for individual self-awareness and through this awareness making personal adjustments for the betterment of the team. The third theme identified by the group members was the significant importance of clear and effective communication skills to facilitate professional interactions. Specifically, it is extremely important to listen and seek to understand before attempting to be understood by another person while working in the team environment. 
The focus group was unanimous in recognizing the level of knowledge and skill provided by Lencioni. The focus group considered use of the book and workbook complementary. The book presented the material in an easily read, nonthreatening manner. The workbook was viewed as a template to process and integrate the material and concepts. This increased the ability of the group to transition the information and concepts into more specific academic settings. Group members could readily recall examples of the lessons for each chapter and the potential application during interactions with other people. The thoughtful process approach as the story unfolded provided examples of how to transition the lessons to the academic environment. The focus group appreciated the details and suggestions provided at the conclusion of the book and identified several suggestions that could be useful in executing their leadership roles.

The focus group opined that knowledge of the skills and talents of each member on a personal level was important to discern how these strengths could benefit the group. The group acknowledged the time investment needed to continue the dynamic process of team building and leadership development. Concerning additional recommendations for application of the process covered in the book, the group recognized the advantages of getting away for scheduled retreats and recommended inclusion of this model. In addition to extended time away for team building and development, the group also recommended scheduling team time regularly, whether short or long, to sustain the work and momentum.

Overall, the focus group was very appreciative of the insights of the other group members. The focus group acknowledged the high level of trust established in the initial sharing session of information. Individual member's willingness to reveal personal information helped the team coalesce. The team members look forward to the next opportunity to work together and learn from each other.

\section{Discussion}

\subsection{Literature review}

To evaluate previous faculty development scholarship, a review of the literature was completed. The role of mentoring to help develop leaders and successful transitioning to administration duties into key or essential positions in the academy is recognized by AACP (Van Amburgh et al., 2010) and the organization has strengthened its focus on leadership development through meeting program topics, the AACP website online resources and its fellows leadership program.

Fuller, Maniscalco-Feichtl, and Droege (2008) highlighted the advantages of mentoring as an effective tool for faculty retention. These advantages included workplace stress reduction, particularly recognizing the area of scholarship that may require an introduction to learning theory and educational culture (Mann, 2011) of the organization. Support for development of interprofessional collaboration for enhanced patient care and potential scholarship was also seen as essential for research program development (Clarke-Tasker, 2009).

While the more traditionally recognized dyad model of mentor-mentee might no longer be an option given the proportion of junior to senior faculty in schools/colleges of pharmacy, involvement of the organization into the model represents one strategy to increase mentorship opportunities. Incorporating the organization into the mentorship model requires an internal paradigm shift in some cases to embrace the bidirectional interaction of thinking and interacting between the college or school and the individual. Team development, from business models, incorporates five categories: system thinking, individual mastery, developing shared visions, team learning, and transitioning from a shared vision to a shared thought process/mental model (Fuller et al., 2008). This model is based on the team process in the collective contributions of the team represent a more appropriate methodology for addressing complex tasks. In addition, it allows for workload sharing, behavior monitoring of the individual members, and development and demonstrations of expertise on aspects of the total project (Mathieu, Heffner, Goodwin, Salas, \& Cannon-Bowers, 2000). In the triad model of mentorship, the organizational component brings in the culture and how it influences the faculty member and how the faculty member affects the organization. Use of this model was associated with improved life-work balance and morale and a decreased potential for burnout (Fuller et al., 2008).

Establishing a clinical practice is a time consuming task for many new academicians that necessitates the use of effective leadership skills. Interprofessional education necessitates the use of team work, enhancement of student educational opportunity and a continual quality improvement process to achieve optimal patient outcome. Collaborative practice initiatives to address costs to institutions are imperative. Jorgenson, Mauger, and Oderd (1998) evaluated a methodology to combine the educational component from a College of Pharmacy and patient care 
service in a hospital system. In addition to shared expenses, the departments of pharmacy services and pharmacy practice developed an integrated working relationship. Although this proposal did not specifically address the importance of teamwork in leadership, integration of service resources has the potential to help alleviate work-life stressors, an area identified by junior faculty as a concern by other studies (Conklin \& Desselle, 2007; Fuller, et al., 2008).

Buring, Bhushan, Brazeau, Conway, Hansen, and Westberg (2009) identified faculty leadership development as a necessary skill set rather than another faculty responsibility. While a specific roadmap for a successful transition into academic or more administrative responsibilities for senior academicians is not currently available, recognition of targeted activities with defined goals and outcomes as a tool for faculty leadership development in academic settings was discussed. One academic institution reviewed the results of a junior faculty development program. Categories included project work, academic productivity focusing on program graduates, and projects as a function of career development. Evidence of the most faculty progress was in the area of academics, specifically products and overall achievements. Based on the literature and program findings, the authors concluded projects are essential to faculty development and form the basis of future academic success. For junior faculty, these activities function to enhance knowledge and skills, help them achieve work-life balance by helping develop collaborative and supportive relationships, and often improve scholarly productivity (Gusic, Milner, Tisdell, Taylor, Quillen, \& Thorndyke, 2010).

Application of the student leadership model for students to junior faculty may represent another avenue for leadership development. The AACP commission included development of a model with five components: modeling, creating a shared vision, challenging the process, providing others opportunities to act, and instilling organization commitment, identified as 'leading from the heart' in the student model (Kerr et al., 2009). This template can be adapted to junior faculty development with few revisions. By challenging the process, students can bring their own innovations and initiatives to the process. By extension, junior faculty can also challenge themselves to develop a skill set for one aspect of academia. Junior faculty can create successful experiences using mentorship models, including the more traditional dyad of mentor-mentee or the triad model, with the organization as the third component (Fuller et al., 2008). One of the elements identified in the Five Dysfunctions of a Team (Lencioni, 2002) leadership resources was the identification of the strengths of each team member and how recognition of these strengths can be utilized to enhance team progress and individual growth. Identification and application of individual strengths have the potential to increase or enhance professional satisfaction, leadership, and empowerment (Traynor, Janke, \& Sorensen, 2010).

\subsection{Management strategies}

Table 1 was adapted from the topics addressed in the workbook. According to Lencioni (2002), the foundation of a team is trust. This fundamental element is the number one item in the workbook. The four additional fundamental elements of mastering conflict, achieving commitment, embracing accountability and focusing on results were addressed during the scheduled meetings by the team members. Clarity of the concept is essential in securing commitment. Creation of a thematic goal, an overriding goal that is a top priority for the team for a select period, was completed. This team's thematic goal was growth and leadership development of the individual team member. The defining objectives for this team included describing a collaborative effort focused on leadership development with others through several routes of communication such as poster or oral presentation and manuscript production. The team members decided to use SMART goals (specific, measurable, attainable, realistic and timely), to support each other to meet deadlines and to prioritize actions to accomplish these goals. The team members identified several opportunities to disseminate their description of the leadership development process based on the Lencioni (2002) book used for study. The team agreed to submit poster abstracts and workshop proposals to national pharmacy professional meetings and to create a manuscript about this project. A timeline for completion of the activities was developed. 
Table 1: Guided discussion topics for leadership strategies

\begin{tabular}{|c|c|c|}
\hline Session & Team Developmental Task & Discussion Topics \\
\hline 1 & Trust & $\begin{array}{l}\text { Identifying the format to be used during the sessions } \\
\text { Session-setting goals } \\
\text { Sharing and consensus building } \\
\text { Personal and behavioral information (cognitive inventory and } \\
\text { leadership characteristics) }\end{array}$ \\
\hline 2 & $\begin{array}{l}\text { Addressing and Understanding } \\
\text { Conflict }\end{array}$ & $\begin{array}{l}\text { Identifying and sharing personal attributes and their impact on each } \\
\text { team member's response to or engagement in conflict } \\
\text { Recognizing how the influence of personal life and professional } \\
\text { interaction history impacts conflict engagement } \\
\text { Identifying influences that affect individuals' engagement in honest, } \\
\text { clear debate } \\
\text { Weighing the influence of an individual's view of behaviors (both } \\
\text { acceptable and unacceptable) resulting in the productive exchange of } \\
\text { differing ideas }\end{array}$ \\
\hline 3 & Consensus Building & $\begin{array}{l}\text { Understanding the importance of setting a single goal } \\
\text { Identifying specified objectives to be achieved within a designated } \\
\text { time period }\end{array}$ \\
\hline 4 & $\begin{array}{l}\text { Individual and Corporate } \\
\text { Accountability }\end{array}$ & $\begin{array}{l}\text { Describing accountability } \\
\text { Describing methods needed to accomplish the team's goal } \\
\text { Identifying individual team members' strength and weaknesses and } \\
\text { how these may impact the attainment of the team's goal }\end{array}$ \\
\hline 5 & Becoming Results Oriented & $\begin{array}{l}\text { Reviewing original goal } \\
\text { Developing a clear method to evaluate and track the progress related to } \\
\text { the achievement of the goal } \\
\text { Stating the key points and insights attained by focusing on results }\end{array}$ \\
\hline
\end{tabular}

\section{Limitations}

This study of utilization of a book club process with the Lencioni (2002) book and associated workbook (2007) as a resource to facilitate faculty development had a number of limitations. These included the small sample size of the focus group although groups may consist of 4 to 10 participants for completion of this type of sociological study (Morgan \& Spanish, 1984). Limited diversity within the group may be an additional limitation. All the participants were senior faculty members, faculty in management positions, or both. While the focus group was interprofessional, involvement of a junior faculty member with at least one year of faculty experience could have offered the perspective of a junior faculty member still transitioning to faculty leadership roles. A senior faculty transitioning into leadership positions or faculty preparing for promotion may find leadership development through this type of book review useful. Faculty members preparing for these career transitions were not represented in the focus group.

This qualitative format, while recognized as a cost-effective method of focused data collection, does have several potential methodological limitations. In this study, there was only one session for evaluation of the focus group assessment. No follow-up session was planned. In addition, the session was held via teleconference. This was offset by the strengths of group homogeneity of gender, language, literacy level, and familiarity with the topic.

\section{Conclusion}

Leadership skills are essential to the academician throughout their professional life. Financial resources available to 
support leadership development are limited. We explored a leadership development activity through a collaborative study and discussion process and found success. The team members hailed from different colleges/schools of pharmacy and brought unique attributes to the team that allowed other members a growth opportunity. The team was successful in completing stated team goals created at the first teleconference meeting including presenting one poster at a national pharmacy meeting, a roundtable discussion at a national pharmacy meeting and dissemination of the process to others through this manuscript.

\section{References}

AACP Cumulative Policies 1980-2008. Policies on Postgraduate Education and Training. Governance, House of Delegates. $\quad$ Retreived $\quad$ October $29, \quad 2012$ from http://www.aacp.org/governance/HOD/Documents/Cumulative\%20Policies,\%201980-2008.pdf.

American Association of Colleges of Pharmacy (AACP). AACP Profile of Pharmacy Faculty 2011-2012. Retreived October 29, 2012, from http://www.aacp.org/career/salarydata/Documents/PPF-1112.pdf

Buring, S. M., Bhushan, A., Brazeau, G., Conway, S., Hansen, L., \& Westberg S. (2009). Keys to successful implementation of interprofessional education: Learning location, faculty development, and curricular themes. American Journal of Pharmacy Education, 73(4), Article 60. http://dx.doi.org/10.5688/aj730460

Clarke-Tasker, V. A. (2009, Winter). Commentary on collaboration: The key to interdisciplinary research. Association of Black Nursing Faculty Journal, 20(1), 25-26.

Conklin, M. H., \& Desselle, S. P. (2007). Job turnover intentions among pharmacy faculty. American Journal of Pharmacy Education, 71(4), Article 62. http://dx.doi.org/10.5688/aj710462

Fuller, K., Maniscalco-Feichtl, M., \& Droege, M. (2008). The role of the mentor in retaining junior pharmacy faculty members. American Journal of Pharmacy Education, 72(2), Article 41. http://dx.doi.org/10.5688/aj720241

Gaither, C. A., Allen, D. D., Anderson, D. C., Leader, W. G., Morgan, L. A., Weber, S. S., \& Williams, J. S. Flynn, A. A. (2009). Report of the 2008-2009 Professional Affairs Committee: The academy's leadership agenda for meeting academic and practice workforce demands through postgraduate professional education. American Journal of Pharmacy Education, 73, Supplement, Article S4. http://dx.doi.org/10.5688/aj7308S04

Guglielmo, B. J., Edwards, D. J., Franks, A. S., Naughton, C. A., Schonder, K. S., Stamm, P. L., Thornton, P., \& Popovich N. G. (2011). A critical appraisal of and recommendations for faculty development. American Journal of Pharmaceutical Education, 75(6), Article 122. http://dx.doi.org/10.5688/ajpe756122

Gusic, M. E., Milner, R. J., Tisdell, E. J., Taylor, E. W., Quillen, D. A., \& Thorndyke L. E. (2010). The essential value of projects in faculty development. Academic Medicine, 85(9), 1484-1491. http://dx.doi.org/10.1097/ACM.0b013e3181eb4d17

Jorgenson, J. A., Mauger, J. W., \& Oderda G. M. (1998, January). Creating a team approach to hospital and college of pharmacy relationships: a strategy to integrate missions to enhance education and patient care. Pharmacy Practice Management Quarterly, 17(4), 67-75.

Kerr, R. A., Beck D. E., Doss J., Draugalis J. R., Huang E., Irwin A., Patel A., Raehl C. L., Reed B., Speedie M. K., Maine L. L., \& Athay J. (2009). Building a sustainable system of leadership development for pharmacy: report of the 2008-09 Argus Commission. American Journal of Pharmacy Education, 73, Supplement, Article S5.

Lencioni, P. (2002). The Five Dysfunctions of a Team: A Leadership Fable (1st ed.). San Francisco, CA: Jossey-Bass.

Lencioni, P. (2007). The Five Dysfunctions of a Team: Participant Workbook. San Francisco, CA: Pfeiffer.

Mann, K. V. (2011). Theoretical perspectives in medical education: past experience and future possibilities. Medical Education, 45(1), 60-68. http://dx.doi.org/10.1111/j.1365-2923.2010.03757.x

Mathieu, J. E., Heffner T. S., Goodwin G. F., Salas E., \& Cannon-Bowers J. A. (2000). The influence of shared mental models on team process and performance. Journal of Applied Psychology, 85(2), 273-283. http://dx.doi.org/10.1037/0021-9010.85.2.273

Morgan, D. L., \& Spanish, M.T. (1984). Focus groups: a new tool for qualitative research. Qualitative Sociology, 
7(3), 253-270. http://dx.doi.org/10.1007/BF00987314

Traynor, A. P., Janke, K. K., \& Sorensen, T. D. (2010). Using personal strengths with intention in pharmacy: implications for pharmacists, managers, and leaders. Annals of Pharmacotherapy, 44(2), 367-376. http://dx.doi.org/10.1345/aph.1M503

Van Amburgh, J., Surratt, C. K., Green, J. S., Gallucci, R. M., Colbert, J., Zatopek, S. L., \& Blouin, R. A. (2010). Succession planning in US pharmacy schools. American Journal of Pharmacy Education, 74(5), Article 86. http://dx.doi.org/10.5688/aj740586

\section{Notes}

Previous presentation: Accepted for a roundtable discussion as: Leadership development through a book club using the Five Dysfunctions of a Team. American Association of Colleges of Pharmacy (AACP) Annual Meeting, San Antonio, TX, July 10, 2011.

Funding Disclosure Statement: No funding was requested or received in conjunction with this project. The authors report no known or suspected conflicts of interest related, but not limited to consulting fees, paid expert testimony, employment, grants, honoraria, patents, royalties, stocks, or other financial or material gain involved with or pertaining to the subject matter of this work.

Conflict of Interest Disclosure Statement: The authors report no actual or possible conflicts of interest, including financial, personal or other relationships with other individuals or organizations that might inappropriately influence or could be perceived to influence our work. 